\title{
COMPARISON OF TRANSIENT AND STATIONARY NEUTRAL PRESSURE RESPONSE IN THE DIII-D ADVANCED DIVERTOR
}

\author{
by \\ C.C. KLEPPER, J.T. HOGAN, \\ L.W. OWEN, P.K. MIODUSZEWSKI, R. MAINGI, \\ D.N. HILL, D. BUCHENAUER, M. ALI MAHDAVI, \\ M.J. SCHAFFER, T.W. PETRIE, G.L. JACKSON, \\ T.E. EVANS, G. HAAS
}

MAY 1992 


\section{DISCLAIMER}

This report was prepared as an account of work sponsored by an agency of the United States Government. Neither the United States Government nor any agency thereof, nor any of their employees, makes any warranty, express or implied, or assumes any legal liability or responsibility for the accuracy, completeness, or usefulness of any information, apparatus, product, or process disclosed, or represents that its use would not infringe privately owned rights. Reference herein to any specific commercial,product, process, or service by trade name, trademark, manufacturer, or otherwise, does not necessarily constitute or imply its endorsement, recommendation, or favoring by the United States Government or any agency thereof. The views and opinions of authors expressed herein do not necessarily state or reflect those of the United States Government or any agency thereof. 


\title{
COMPARISON OF TRANSIENT AND STATIONARY NEUTRAL PRESSURE RESPONSE IN THE DIII-D ADVANCED DIVERTOR
}

\author{
by \\ C.C. KLEPPER,* J.T. HOGAN, * L.W. OWEN,* \\ P.K. MIODUSZEWSKI, ${ }^{*}$ R. MAINGI, D.N. HILL, $\ddagger$ \\ D. BUCHENAUER, $\$$ M. ALI MAHDAVI, M.J. SCHAFFER, \\ T.W. PETRIE, G.L. JACKSON, T.E. EVANS, G. HAAS \\ *Oak Ridge National Laboratory \\ † North Carolina Jtate University \\ ‡Lawrence Livermore National Laboratory \\ $\S$ Sandia National Laboratory \\ IMax-Planck-Institut-für-Plasmaphysik
}

This is a preprint of a paper to be presented at the 10th International Conference on Plasma Surface Interactions, March 30 through April 3, 1992, Monterey, California and to be printed in the Proceedings.

Work supported by

Department of Energy

Contract DE-AC03-89ER51114

GENERAL ATOMICS PROJECT 3466

MAY 1992

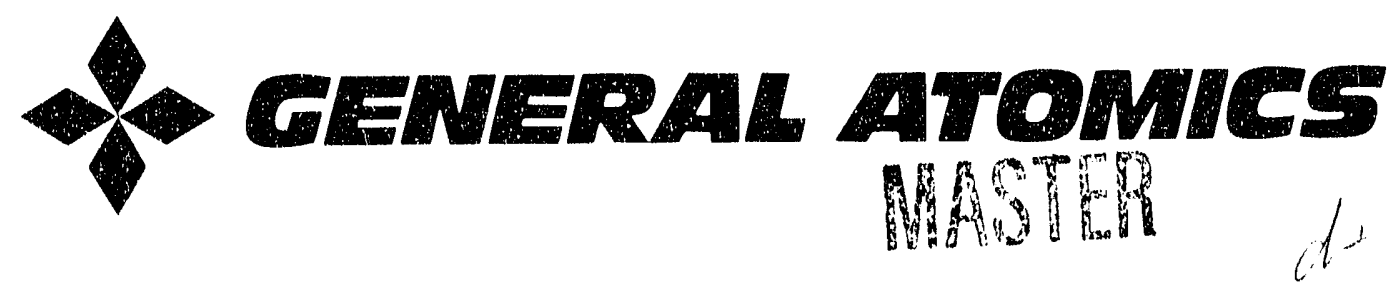

DISTRIBUTION OF THIS OBCUMENT IS UNLIMITEO 


\title{
Comparison of Transient and Stationary Neutral Pressure Response in the DIII-D Advanced Divertor
}

\author{
C.C. Klepper, ${ }^{*}$ J.T. Hogan, P.K. Mioduszewski, M. Ali Mahdavi,, R. Maingi, ${ }^{\dagger}$ \\ L.W. Owen, M.J. Schaffer, ${ }^{\circ}$ D. Buchenauer, $\$$ T.E. Evans, ${ }^{\ominus}$ J.G. Gilligan, ${ }^{\dagger}$ \\ G. Haas, I D.N. Hill, $\mathfrak{L}$ G.L. Jackson,, T.W. Petrie ${ }^{\searrow}$ \\ Oak Ridge National Laboratory, Oak Ridge, Tennessee 37831, USA
}

The DIII-D divertor baffle system was designed to facilitate density control in long pulse $\mathrm{H}$-mode discharges by removing a particle flux equal to the neutral beam fueling rate $(\sim 20$ Torr-1/s) with a $\sim 1 \mathrm{mTorr}$ neutral pressure under the baffle $\left(\mathrm{p}_{0}\right)$. Initial measurements of the baffle pressure indicated that $\mathrm{p}_{0} \sim$ $10 \mathrm{~m}$ Torr (without pumping or biasing), a value much in excess of that required for long pulse density control. Radial sweeps of the $X$-point position have been employed to determine the maximum $p_{0}$, as well as to establish the dependence of this pressure on geometry. An estimate of the particle equilibration time for the baffle system has been made by studying the baffle pressure response to "giant" ELM effects. "Steady state" experiments in which the X-point position was fixed for $\sim 2.5 \mathrm{~s}$ have also been carried out and steady baffle pressures were observed. The scaling of baffle pressure with plasma parameters has been found to be similar under transient and "steady state" conditions. Detailed modeling of these experiments with the B2, DEGAS, and WDIFFUSE (wall model) codes has been made.

\footnotetext{
*Present address: General Atomics, San Diego, California

General Atomics, San Diego, California

†North Carolina State University, Raleigh, North Carolina

\$Sandia National Laboratory, Livermore, California

IMax-Planck-Instittue-für-Plasmaphysik, Garching, Germany

ELawrence Livermore National Laboratory, Livermore, California
} 


\section{Introduction}

As a part of the Collaborative Advanced Divertor Program on DIII-D, M.A. Mahdavi [1], a baffled plenum has been installed in DIII-D, in which high neutral pressures may be produced by moving the plasma strike point outward, to the optimal location for filling the baffle plenum (Fig. 1). With the (future) addition of a pump inside this region, particle control can be accomplished. To exhaust the beam fueling source in DIII-D ( 20 Torr $1 / \mathrm{s})$ in long pulse $(\sim 10 \mathrm{~s})$ $\mathrm{H}$-mode plasmas, pressures of $\sim 1$ mTorr (with pumping) will be required, P.K. Mioduszewski [2].

Initial experiments with the outer divertor intercept placed near the throat of the baffle region readily demonstrated (unpumped) pressures in excess of 3 mTorr, M.A. Mahdavi [3]. These pressures were found to be consistent with the injected power, scrapeoff layer plasma transport, and presumed local recycling properties, C.C. Klepper [4]. These first studies swept the radial position of the outer separatrix strike point in time to examine the dependence of the baffle pressure $p_{0}$ with the change in magnetic geometry. The strike point was in the region of the optimal baffle pressure for $\sim 0.5 \mathrm{~s}$ in each case. In modeling analysis, agreement of the measured baffle pressure with B2 and DEGAS calculations was found to require the assumption of additional local recycling from the bias ring. (This assumption was suggested by the observation of increased scrapeoff layer electron temperature and density $\left(\mathrm{T}_{\mathrm{e}}\right.$ and $n_{\mathrm{e}}$ ) measured by Thomson scattering in the midplane). 


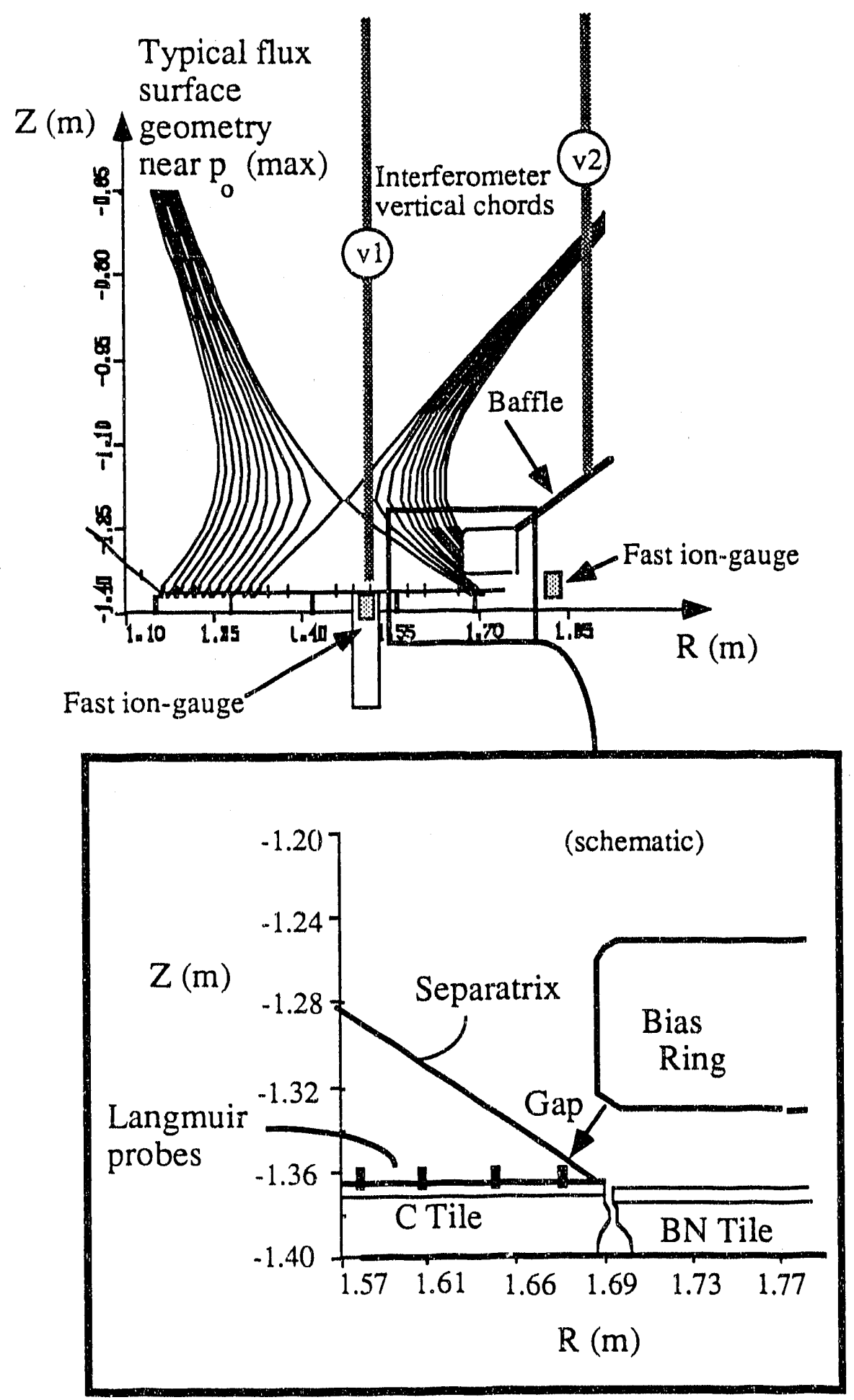

Fig. 1. Schematic of the experimental layout in DIII-D. 
The studies described here seek to improve our understanding of the observed baffle pressures by direct experimental study of the additional source of recycling near the bias ring which was required in B2 modeling of "transient" sweeping experiments. The origin of this recycling source is investigated with two complementary experiments: on the very short time scale $(20 \mathrm{~ms})$ iighly transient "giant ELM" events are observed to cause a significant drop in the core plasma content and a large increase in the baffle pressure. Analysis of the divertor-baffle system time response during such events sheds some light on the local recycling conditions in the baffle region. On a longer time scale $(\sim 1-3 \mathrm{~s})$, we moved the separatrix strike point to a near-optimal position for baffle pressure, then kept the position fixed for $\sim 2.5 \mathrm{~s}$ to look for possible change (growth or decay) of the pressure at long times. It is expected that the full plasma core-wall system will require at least $10 \mathrm{~s}$ to establish a steady state, since the equilibration time is determined by the state of saturation of wall surfaces far from the divertor which receive relatively low particle fluxes. Hence, the steady state baffle pressure is expected to change on this longer time scale. However, the particle flux to the divertor tile area is much larger than that of these distant wall components in DIII-D, and we expect that local equilibration in the baffle entrance area can be established more quickly. To estimate the response time of the particle reservoir in the divertor tiles near the baffle, we have modeled the time response of the tile efflux during transient experiments with a diffusion code (WDIFFUSE) which follows the evolution of the hydrogen density in the amorphous carbon-hydrogen co-deposition $(\mathrm{aC}: \mathrm{H})$ layer. 


\section{Experimental setup, baffle pressure diagnostics, and model description}

\subsection{Experimental setup}

In these experiments, plasma parameters were monitored with standard DIII-D diagnostics. In particular, Thomson scattering was used for both electron temperature and electron density profiles. This diagnostic has a high spatial resolution at the edge $(\sim 1.3 \mathrm{~cm})$ and its $25 \mathrm{~ms}$ duty cycle allows for a time resolution compatible with that of the pressure measurements. The divertor tile Langmuir probes, D. Buchenauer [5], form a radial array of single-tip probes. The outermost probe tip is about $2 \mathrm{~cm}$ radially inward from the inner edge of the bias ring. Thus, direct measurements of divertor parameters cannot be made when the strike point is near the optimal positions for baffle pressure. Finally, the lower divertor Infrared camera (IR TV) was used to monitor the power flux density at the outer divertor intercept. The camera views from the top of the machine and converts infrared thermal emission to a calculated temperature of the graphite tiles in its field of view. From this, the divertor heat flux can be inferred, D.N. Hill [6]. For these experiments, though, the region of peak heat flux density can be shadowed by the ring. For this reason, heat flux profiles for the analysis must be obtained from measurements when the outer divertor intercept is away from the ring and in the neighborhood of the Langmuir probes.

The geometry for conditions of maximum pressure was determined by the EFITD magnetic fitting code, L.L. Lao [7,8]. The code produces an optimal least squares fit to the magnetic probe data on DIIi-D. For these experiments, the determination of the magnetic geometry in the region near the floor of the vessel requires inclusion of current density profiles with edge currents flowing 
in the scrapeoff layer. The separatrix position near the lower floor can only be determined to within $\sim 1 \mathrm{~cm}$, with the existing magnetic diagnostics on DIII-D.

\subsection{Baffle pressure diagnostics}

The pressure under the baffle was miasured with a fast ionization gauge, originally developed at IPP-Garching, G. Haas [9]. The gauge is is capable of fast time response $(<5 \mathrm{~ms})$, primarily because it operates with the $1.5-2.1 \mathrm{~T}$ toroidal field and thus may be located in the region of interest inside the primary vacuum vessel. Aside from the primary gauge, located under the divertor baffle, a second gauge was located at a port in the floor of the machine. In a single-null diverted discharge, this gauge is located approximately under the $\mathrm{X}$-point and measures the pressure in the private flux region. The gauges were calibrated over a large range of pressures against a capacitance manometer while the machine was filled with deuterium. Both gauges are built inside a stainless steel housing designed to protect the gauge from direct exposure to ions or energetic neutrals. These housings, which are equipped with narrow entrance slits and internal baffles to assure particle thermalization, are responsible for the upper limit to the time response in the range of $5-10 \mathrm{~ms}$. The response time for the pressure measurements under the baffle is further increased by the fill-up time of the baffle plenum. Assuming molecular conductance, the fill-up time of the plenum is about $36 \mathrm{~ms}$. Plasma-neutral interactions are expected to decrease the conductance, A. Hardtke [10]. 


\subsection{Wall model}

The wall model consists of a semi-empirical one-dimensional diffusion equation solving for the $\mathrm{H}$ diffusion in the $\mathrm{aC}: \mathrm{H}$ layer in the divertor region. The model is patterned after the DIFFUSE cole used to describe the hydrogen content, first in metal surfaces, and lately in graphite layers, M.I. Baskes [11]. We treat deposition, diffusion, and emission from the surface with the equation

$$
\frac{\partial N_{H}}{\partial t}=D_{H} \frac{\partial^{2} N_{H}}{\partial x^{2}}+S_{H}
$$

where the diffusivity is assumed to be $D_{H}=D_{0} e^{-E_{D}} / k T_{\text {wall }}$, with $D_{0}=3 \times 10^{-3} \mathrm{~m}^{2} / \mathrm{s}$ and $E_{D}=0.7 \mathrm{eV}$. The deposition source $S_{H}$ is an energy-dependent source of $H$ deposited in the aC:H layer, with contributions from incident ion implantation. The ions incident on the divertor plate are assumed to be accelerated by the sheath potential and have an energy up to $E \sim 100 \mathrm{eV}$. The local diffusivity $D_{H I}(x)$ is enhanced by a factor 10 where $n_{H}>0.4 n_{C}$ to ensure that $n_{H}$ is limited to $0.4 n_{C}$ and that saturation is thus modeled. The area modeled is assumed to be $0.4 \mathrm{~m}^{2}$, based on the width of the peak divertor fluxes at the divertor plate.

\section{Review of radial sweep experiments and results}

Previous radial-sweep ("transient") experiments, C.C. Klepper [4], determined the optimal position of the outer divertor intercept with respect to the bias ring. The sweeps were made at a sufficiently slow rate to allow equilibration of the pressure under the baffle at each position, covering approximately $5 \mathrm{~cm}$ in radial extent in $1400 \mathrm{~ms}$. In these experiments, the position of the divertor strike point with respect to the baffle aperture was found 
to be an important variable in determining both the flux of particles to the plenum, and the interaction of the plasma with the baffle structure. The separatrix at a time near that of maximum pressure had about a $2.4 \mathrm{~cm}$ clearance with the beveled edge of the bias ring for $P_{\mathrm{NB}} \sim 7.5 \mathrm{MW}$, rising to $\sim 3 \mathrm{~cm}$ for $\mathrm{P}_{\mathrm{NB}}$ $\sim 14.2 \mathrm{MW}$. Since the optimum position is relatively close to the gap between the $\mathrm{C}$ and BN tiles (see Fig. 1), there is a possibility of enhanced recycling from this area and the dependence of pressure on aperture conditioning must be examined.

This possibility was underscored by simulations of the radial sweep experiments with the B2 edge transport code, C.C. Klepper, B.J. Braams [4,12]. The simulations matched the available data and obtained estimates of the particle fluxes at the baffle aperture. DEGAS, D.B. Heifetz [13], calculations using those fluxes obtained agreement with the measured baffle pressure. An important result of these $B 2$ calculations was the need to add an additional source of recycling from the bias ring, occurring as the $X$-point was moved to the near-optimum position. The calculation postulated a local recycling coefficient of unity both on the front of the bias ring and at the location of the baffle entrance, under the assumption that there is flux balance between the SOL and the baffle aperture in steady state. Thus two separate effects were included in previous B2 modeling: the recycling of particles scraped off on the front of the bias ring and local fueling of the scrapeoff layer by the back-conductance of neutral flux from the (unpumped) baffle plenum. One goal of the present experiment is to attempt to distinguish between these sources. 


\section{Short and long time scale experiments}

\subsection{Short time scale experiments}

Analysis of so-called "giant ELM" events affords a direct way to explore the coupling between the plasma core and the baffle region. As seen in Fig. 2, there is a significant drop in the plasma particle content accompanied by a rise in the divertor neutral pressure during such an occurrence. Since there is a significant rapid drop in the particle content of the plasma core, it is instructive to estimate how much of this efflux finds its way to the baffle plenum. Since the particle source is strongly localized in time, the correlation of the baffle and SOL behavior is facilitated.

Table 1 compares the particle content in the plasma core, in the baffle region, and in the entire system (core plus baffle) before, during, and after a "giant ELM" event at $t \sim 2300$ ms. The core content drops from $9 \times 10^{20}$ particles (electrons) to $7 \times 10^{20}$ particles. Using the measured pressure in the baffle, we find that the particle content there (expressed in terms of equivalent electrons, or molecules times 2) is increased from $1 \times 10^{20}$ to $2 \times 10^{20}$ particles, so that the additional number of equivalent electrons in the baffle is roughly equal to the number of electrons lost from the core. However, the situation is more complicated: because of local flux amplification in the divertor, there is the possibility that much of the baffle pressure increase is due to increased recycling from the divertor floor in front of the aperture. (Previous modeling of transient baffle pressure experiments suggests that the flux amplification factor $(A)$ is in the range 10-30). Thus, complete equivalence of the number of particles lost from the core to the the increased number in the baffle may, in fact, represent an 


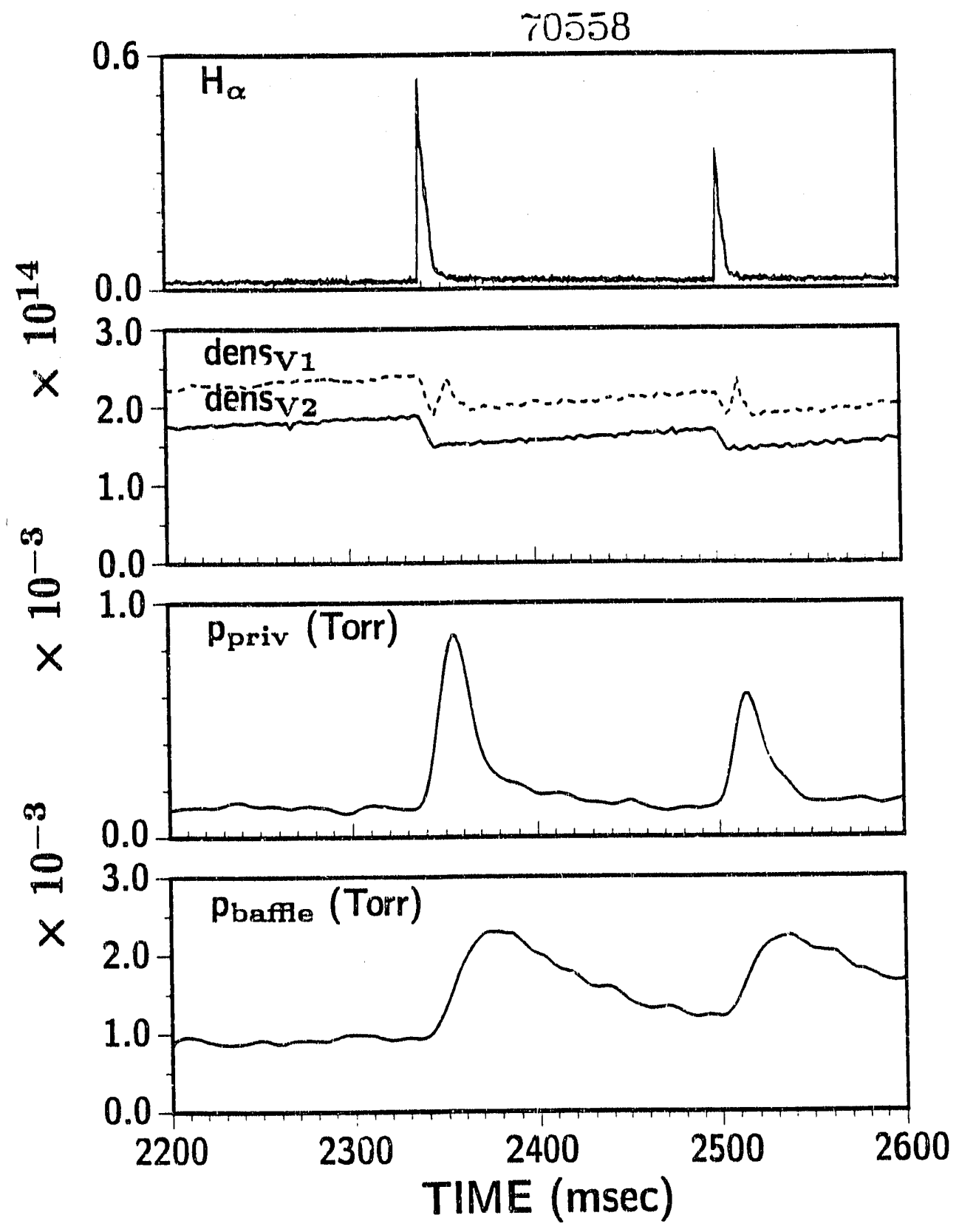

Fig. 2. Giant ELM in a low power H-mode discharge with the outer divertor strike region near the entrance of the baffle region: (a) $\mathrm{Ha}_{\mathrm{a}} / \mathrm{D}_{\mathrm{a}}$ emission showing the time history of the ELMs; (b) two line integrated electron density chords, one passing through the divertor (dashed line) and one missirig the divertor (solid line); (c) the pressure in the private flux region as affected by the ELMs; (d) the pressure under the baffle as affected by the ELMs. 
Table 1

Particle Inventory in the Plasma Core and in the Baffle Region

\begin{tabular}{cccc}
\hline $\begin{array}{c}\text { Time } \\
(\mathrm{ms})\end{array}$ & $\begin{array}{c}\text { Core Plasma } \\
\text { Electrons }\end{array}$ & $\begin{array}{c}\text { Baffle } \mathrm{D}_{2} \\
\text { Molecules }\end{array}$ & $\begin{array}{c}\text { Total Number } \\
\text { of Molecules }\end{array}$ \\
\hline 2325.0 & $8.88 \times 10^{20}$ & $5.03 \times 10^{19}$ & $4.94 \times 10^{20}$ \\
2375.0 & $7.07 \times 10^{20}$ & $12.4 \times 10^{19}$ & $4.77 \times 10^{20}$ \\
2425.0 & $7.54 \times 10^{20}$ & $8.89 \times 10^{19}$ & $4.66 \times 10^{20}$ \\
\hline
\end{tabular}

actual particle transfer efficiency as low as $\sim 3-10 \%$ (assuming $A=30-40$ ). DEGAS estimates of the "flux capture" efficiency of the baffle aperture suggest numbers in the range 5-10\%. Note that the baffle only captures particles recycled at the outer strike point. Experiments on $E^{\mathrm{T}} 1 /$ power loss suggest that the bulk of the power, and very likely of the particle, transport is to the inner strike point, D.N. Hill [14]. Thus, this result suggests that particle fluxes to the inner strike point are recycled there to provide scrapeoff layer fueling, and the particles can eventually be collected in the baffle located on the outer strike point.

Figure 2(b) shows a comparison of the density interferometer chords dens $_{\mathrm{V} 1}$ (which includes the divertor region, see Fig. 1) and dens 2 (mostly core plasma). The density histories seen on chords dens $\mathrm{V}_{1}$ and dens 2 differ. The core electron density drops sharply at the time of the "giant ELM" event on chord dens $_{\mathrm{V} 2}$, and slowly recovers on the $t_{\mathrm{p}}$ time scale. As seen on chord densv1, which includes the divertor region, the initial drop in $n_{\mathrm{e}}$ is followed in $\sim 10 \mathrm{~ms}$ by an increase in the number of electrons. The increase in $n_{\mathrm{e}}$ on chord dens 2 occurs at the same time as the pressures in the baffle and in the private flux 
region rise. The observed rate of rise in the private flux region pressure can be no faster than its instrumental time constant $(\sim 5 \mathrm{~ms})$, as discussed above, while the baffle pressure rises on a time scale of about the baffle filling time $(35 \mathrm{~ms})$. The decay of pressure in the baffle shows a longer time constant, and it matches the time decay of pressure in the private flux region. Thus, both time responses indicate directly the effect of local recycling. The pressures in the baffle and in the private flux region rise with the increased particle fluxes during the ELM event, and as they rise there is an additional fueling source for the SOL plasma. Thus, the particle flux to the strike point consists both of the direct flux from the core and the flux due to back conductance from the baffle and the private flux region.

\subsection{Long time scale experiments}

In order to further explore the mechanism for the additional recycling in the vicinity of the bias ring, experiments were conducted in which the $X$-point was moved to a near-optimal position for the baffle pressure, then kept at that position for $\sim 2.5 \mathrm{~s}$. The baffle pressure, the core electron density, and the divertor $\mathrm{H}_{\alpha} / \mathrm{D}_{\alpha}$ emission (averaged over the ELMs) were constant during this period. The dependence of these steady state pressures on plasma parameters can be compare $d$ with the dependence measured under transient conditions. In the radial sweep experiments in $\mathrm{H}$-mode, we observed an approximately linear dependence of baffle pressure on injected power ( $\mathrm{p}_{\mathrm{baffle}} / \mathrm{P}_{\mathrm{inj}} \sim$ constant). Also, we found a strong dependence on the distance between the separatrix and the face of the bias ring (ring-separatrix gap in Fig. 1). Since two boronizations and one minor carbonization of the DIII-D vessel occurred in the time period 
between the radial sweep and steady state experiments, J. Phillips [15], we must adjust for possible changes in the core efflux due to changes in the wall conoitions. Thus, we have normalized the ratio of pressure to injected power to the core density, examining the ratio $\left(\mathrm{p}_{\mathrm{baffle}} / \mathrm{P}_{\mathrm{inj}}\right) / \bar{n}_{\mathrm{e}}$ for the $\mathrm{H}$-mode shots of both series. We plot this product against the ring-separatrix gap in Fig. 3. With this normalization, the pressures from the two experiments show the same dependence on geometry, as seen in the figure. It would appear, then that the transient sweep experiments, with $\sim 0.5 \mathrm{~s}$ dwell in the region of optimal pressure, produce an equilibiated state in the particle reservoir near the bias ing. To support this finding, we have modeled the particle flux response of the tiles during the radial sweep of the divertor strike point.

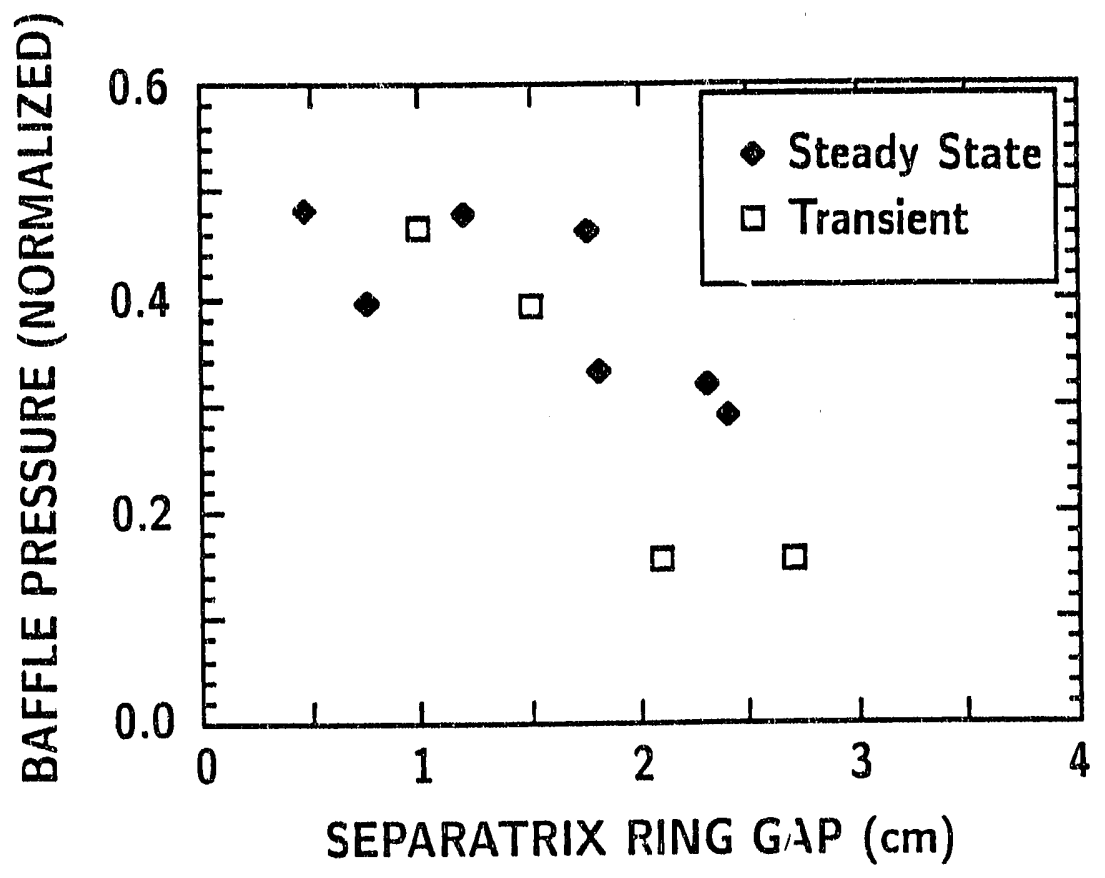

Fig. 3. Baffle pressure, normalized by injected power and chord-averaged electron density, plotted versus the ring-separatrix gap. 


\subsection{Transient time response of the tile particle reservoir}

To model (with WDIFFUSE) the plate response to transient sweeping, we divide the floor into 10 zones, extending from $R=160 \mathrm{~cm}$ to $R=170 \mathrm{~cm}$ (position of the face of the bias ring) and assume the incident particle flux has the form

$$
\begin{aligned}
\Gamma(\mathrm{R}, t) & =\Gamma_{0}(t)\left[1-\left(\mathrm{R}-\mathrm{R}_{\mathrm{sep}}\right) / \mathrm{D}\right], & & \mathrm{R}_{\mathrm{sep}}(t)<\mathrm{R}<\mathrm{R}_{\text {sep }}(t)+\mathrm{D} \\
& =0, & & \mathrm{R}>\mathrm{R}_{\mathrm{sep}(t)}+\mathrm{D} \text { or } \mathrm{R}<\mathrm{R}_{\mathrm{sep}(t)}
\end{aligned}
$$

where $D=4 \mathrm{~cm}$ (the width of the IR TV heat flux peak on the divertor floor). The particle influx is assumed to increase from $4.4 \times 10^{19} \mathrm{~cm}^{2} \mathrm{~s}^{-1}$ at $R=160 \mathrm{~cm}$ (away from the ring) to $1.3 \times 10^{20} \mathrm{~cm}^{-2} \mathrm{~s}^{-1}$ at $\mathrm{R}=170 \mathrm{~cm}$. The values are taken from B2 simulations of the radial sweep experiments, and use the measured Thomson scattering values for $n_{\mathrm{e}}$ and $\mathrm{T}_{\mathrm{e}}$ at the midplane as boundary conditions, C.C. Klepper [4]. The influx is shown in Fig. 4(a) and the computed reflux from the C:H layer in the tiles is shown in Fig. 4(b). The reflux is seen to follow the influx with $\sim 10 ?-200$ ms time constant, showing that the tile particle reservoir comes into equilibrium during the radial sweeps. This supports the observation that the pressure dependence in the steady state experiment is similar to that in the radial sweep experiments shown in Fig. 3.

\section{Discussion}

The long time scale experiments show that the baffle pressures previously only observed under transient separatrix-sweeping conditions can be sustained for times up to $2.5 \mathrm{~s}$. They are thus relevant for experiments on long-pulse H-mode density control. The back conductance of gas from the (now unpumped) baffle has been shown to play a role in local divertor recycling in the 

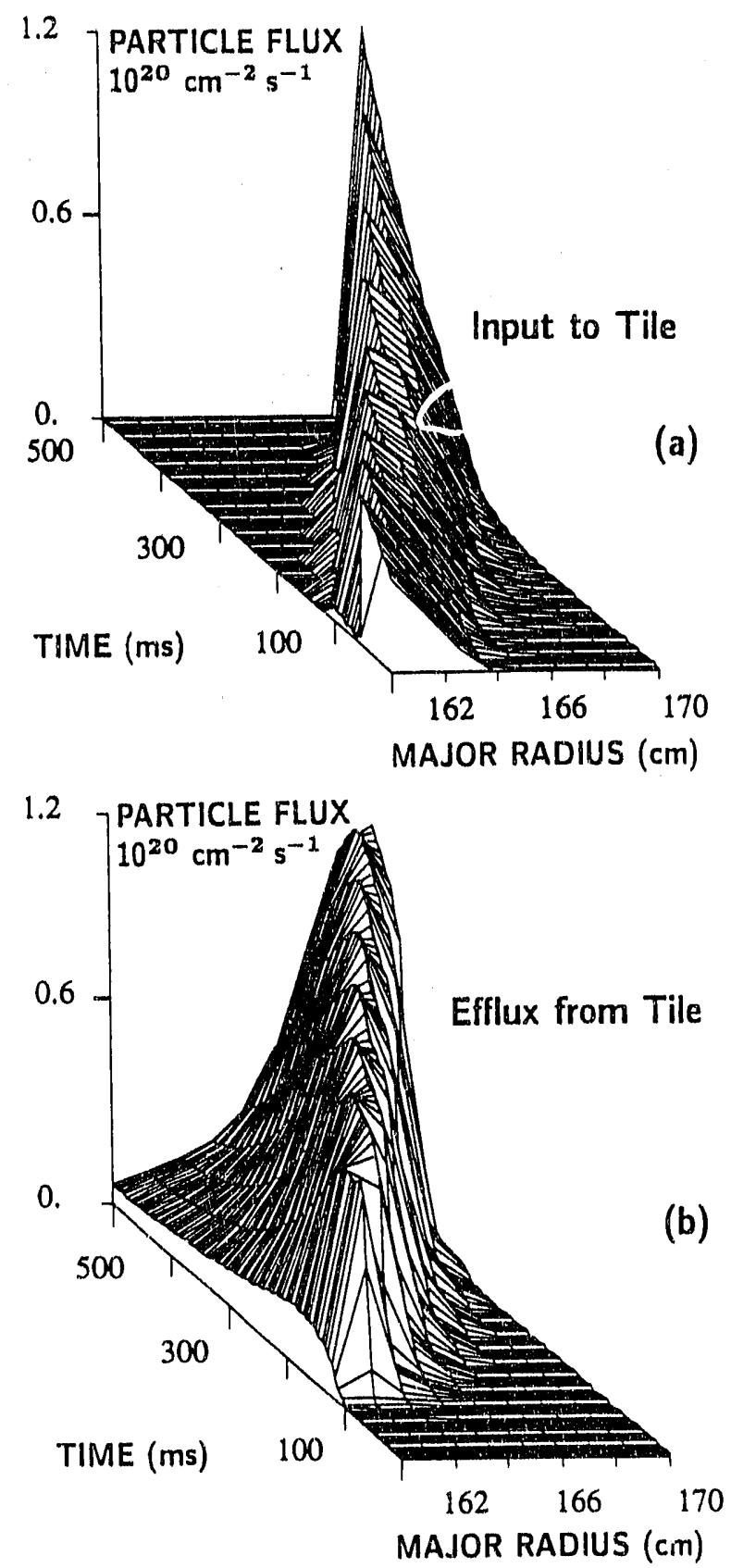

Fig. 4. Results of the wall model for time response of the tiles fluxes during transient experiments: (a) input flux due to separatrix sweeping, with the magnitude of the flux rising as the separatrix approaches the bias ring; (b) modeled response of the efflux from the tiles, showing the attainment of steady state in 100-200 ms. 
region near the bias ring. Such an additional recycling source was required to explain the magnitude of the observed high baffle pressures with B2 and DEGAS, and the determination of the magnitude of this source when the DIII-D Advanced Divertor cryopump is installed is thus identified as a key experimental question for the pumping experiments. The steady state experiments showed the same dependence on geometry as the radial sweep experiments, when account was taken for differing wall conditions. This finding has been supported by modeling of the time scale for response of the fluxes from the divertor tiles, showing that equilibration is reached in $100-200 \mathrm{~ms}$ in this region of high incident flux. The much slower equilibration time of the global recycling will be explored in future long-pulse experiments.

\section{Acknowledgements}

The authors wish to thank Dr. R.D. Stambaugh for his support and encouragement in this work. The technical support from R. Ellis of LLNL and T. Rayburn of ORNL in the construction and installation of the fast ion gauge assembly under the baffle is also acknowledged. The valuable advice obtained from Dr. T. Carlstrom on the use of Thomson Scattering and Infrared Interferometry data was greatly appreciated. This work was supported by the U.S. Department of Energy under Contract Nos. DE-AC05-84OR21400 (Martin Marietta Ener;y Systems, Inc.) and DE-AC03-89ER51114 (General Atomics). 


\section{References}

[1] M.A. Mahdavi, M. Schaffer, P. Mioduszewski, et al., "The DIII-D Collaborative Advanced Divertor Program," GA Report, General Atomics, GA-A19547 (February 1989).

[2] P.K. Mioduszewski, W.L. Owen, M.M. Menon, J.T. Hogan, J. Nucl. Mater. $\underline{176 / 177}(1990) 733$.

[3] M.A. Mahdavi, et al., in: Proc. Plasma Physics and Controlled Nuclear Fusion Research (IAEA, Washington, D.C., 1990) Vol. 1, IAEA-CN-53/ A-IV-7 (1991) p. 335.

[4] C.C. Klepper, J.T. Hogan, D.N. Hill, et al., "Divertor Neutral Pressure Enhancement with a Baffle in DIII-D," GA Report, General Atomics, GA-A20774, to be submitted to Nucl. Fusion.

[5] D. Buchenauer, et al., Rev. Sci. Instrum. 61 (1990) 2873.

[6] D.N. Hill, R. Ellis, W. Ferguson, et al.. Rev. Sci. Instrum. 59 (8) (1988) 1878.

[7] I..L. Lao, H. St. John, R.D. Stambaugh, et al., Nuclear Fusion, 25 (11) (1985) 1611.

[8] L.L. Lao, J.R. Ferron, R.J. Groebner, et al., Nuclear Fusion 30 (6) (1990) 1035.

[9] G. Haas, J. Gernhardt, M. Keilhacker, et al., J. Nucl. Mater. 121 (1984) 151.

[10] A. Hardtke, et al., J. Nucl. Mater. 162/164 (1989) 661. 
[11] M.I. Baskes, "DIFFUSE 83," SNLA Report, Sandia National Laboratories, Albuquerque, SAND 83-8231 (1983).

[12] B.J. Braams, "A Multi-Fluid Code for Simulation of the Edge Plasma Turbulence in Tokamaks," NET Report, Next European Torus Team, EUR-FU/XII-80/87/68 (1987).

[13] D.B. Heifetz, J. Comput. Phys. 46 (1982) 309.

[14] D.N. Hill, et al., in: Proc. Plasma Physics and Controlled Nuclear Fusion Research (IAEA, Washington, D.C., 1990) IAEA-CN-53/G-I-3 (1991) p. 487.

[15] J. Phillips, T. Hodapp, K. Holtrop, et al., "Initial Boronization of the DIII-D Tokamak," GA Report, General Atomics, GA-A20750 (1991). 


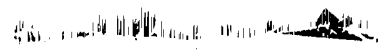

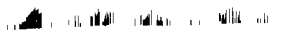


